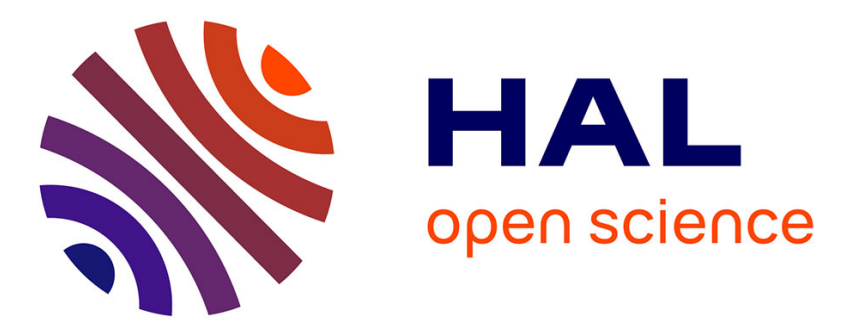

\title{
PLANNING OF LOW VOLTAGE AC/DC MICROGRID FOR UN-ELECTRIFIED AREAS
}

Kimsrornn Khon, Vannak Vai, Marie-Cécile Alvarez-Herault, Long Bun, Bertrand Raison

\section{- To cite this version:}

Kimsrornn Khon, Vannak Vai, Marie-Cécile Alvarez-Herault, Long Bun, Bertrand Raison. PLANNING OF LOW VOLTAGE AC/DC MICROGRID FOR UN-ELECTRIFIED AREAS. CIRED 2021, Sep 2021, Genève (virtual), Switzerland. hal-03324219

\section{HAL Id: hal-03324219 https://hal.science/hal-03324219}

Submitted on 23 Aug 2021

HAL is a multi-disciplinary open access archive for the deposit and dissemination of scientific research documents, whether they are published or not. The documents may come from teaching and research institutions in France or abroad, or from public or private research centers.
L'archive ouverte pluridisciplinaire HAL, est destinée au dépôt et à la diffusion de documents scientifiques de niveau recherche, publiés ou non, émanant des établissements d'enseignement et de recherche français ou étrangers, des laboratoires publics ou privés. 


\title{
PLANNING OF LOW VOLTAGE AC/DC MICROGRID FOR UN-ELECTRIFIED AREAS
}

\author{
Kimsrornn Khon ${ }^{1,2 *}$, Vannak Vai ${ }^{1}$, Marie-Cécile Alvarez-Herault ${ }^{2 * *}$, Long Bun ${ }^{1}$, \\ Bertrand Raison ${ }^{2}$ \\ ${ }^{1}$ Electrical and Energy Engineering Department, Energy Technology and Management Unit, \\ Institute of Technology of Cambodia, 120404 Phnom Penh, Cambodia \\ ${ }^{2}$ Univ. Grenoble Alpes, CNRS, Grenoble INP*, G2Elab, 38000 Grenoble, France \\ *Institute of Engineering Univ. Grenoble Alpes \\ e-mail:*kimsrornn.khon@g2elab.grenoble-inp.fr /**marie-cecile.alvarez@g2elab.grenoble-inp.fr
}

Keywords: K-means, MILP, Optimization, Discount cost, AC/DC microgrid

\begin{abstract}
This paper presents a new AC/DC microgrid topology as an alternative to the traditional AC network in the context of developing countries' electrification. The K-means clustering is employed to pack DC loads into a number of clusters. Next, the minimum spanning tree (MST) is applied to the clusters in order to get the minimum length of DC conductors. Hence, by using the shortest path (SP), the closest electrical poles connected to a cluster at which the AC/DC converter is placed, are found and then, balanced by the mixed-integer linear programming (MILP). Finally, the AC lines connecting all poles and clusters are designed with the MST. The optimal cost of the complete AC/DC microgrid is determined for 20 years of operation.
\end{abstract}

\section{Introduction}

Recently, the microgrid is the popular challenging topic of researchers since it can operate in both grid-connected or island mode while, the development of distributed energy resources, operated in DC form like; solar photovoltaic and battery energy storage is increasing [1]. Indeed, many of today's consumer loads are DC loads such as computers, TVs, chargers, LED lights. So, there are some factors to motivate the LV power system to become DC. To deal with these technological trends, AC/DC microgrids could be an alternative option for rural electrification planning in developing countries and particularly in rural areas [2]. In terms of planning of low voltage AC network, researchers focus on the location and the sizing of the system to supply the electricity to the end-user through conductors [3]. In [4], the authors minimize the length of the conductors using the mix-integer quadratically constraints programming (MIQCP), then the balancing of the load has been performed to respect the technical constraints in the new expansion planning case.

Additionally, the authors have proposed a novel algorithm to optimize the AC topology and phase balancing to deal with the load demand uncertainty[5]. Furthermore, the PV and the battery storage system have been sized and located in order to respect the voltage and the current constraints using a genetic algorithm [6] and [7]. However, most researchers have only focused on the AC distribution system with $\mathrm{AC}$ consumers. Therefore, this paper presents a novel algorithm to pack DC loads into clusters in such a way that the $\mathrm{AC}$ main feeder could supply DC loads by using the AC/DC converter in each cluster. Next, the shortest path (SP) algorithm also finds the optimal location of converters regarding the power losses in the DC structure. Consequently, the load allocation of each phase was formulated by using the mixed-integer linear programming (MILP) solver of MATLAB. The minimum spanning tree (MST) algorithm also aims at searching for the minimum length to get the optimal topologies of each cluster in order to obtain an optimal topology and cost of the AC/DC microgrid. This topology enables a step by step electrification of countries without requiring heavy investments at the intial year. In that way, the electrification of developing countries could go faster with the development of DC microgrids before being connected to the $\mathrm{AC}$ grid when it will be available.

In this paper, we propose a methodology to design the $\mathrm{AC} / \mathrm{DC}$ microgrid in order to get the optimal cost of the system. In section 2, it describes the proposed method subdivided into four stages: the K-means clustering technique for grouping DC loads (consumers) into a given number of clusters (stage 1), the minimum spanning tree to get the minimum total length of conductor in each cluster (stage 2), the shortest path finding the shortest distance of the connection between poles and clusters (stage 3), and the balance of power consumption between the main feeders (stage 4). Section 3 provides the case study in a rural area including the results and discussions. Finally, the conclusions and future works are presented in Section 4.

\section{Methodology}

Fig. 1 shows the proposed method to design the AC/DC distribution microgrid.

It consists of the following steps:

- Step 1: DC loads have been packed into a given number of the cluster by K-means clustering.

- Step 2: Searching the minimum connection of DC conductors in the cluster by using the minimum spanning tree (MST) algorithm. 
- Step 3: The shortest path (SP) finds the shortest distance between households in clusters and poles, on which optimal converters are placed, based on minimal DC losses.

- Step 4: The load allocation of each phase was formulated by using the mixed-integer linear programming (MILP) solver to improve the balance of power consumption between phases.

Finally, the optimal topology and the total discount cost have been calculated.

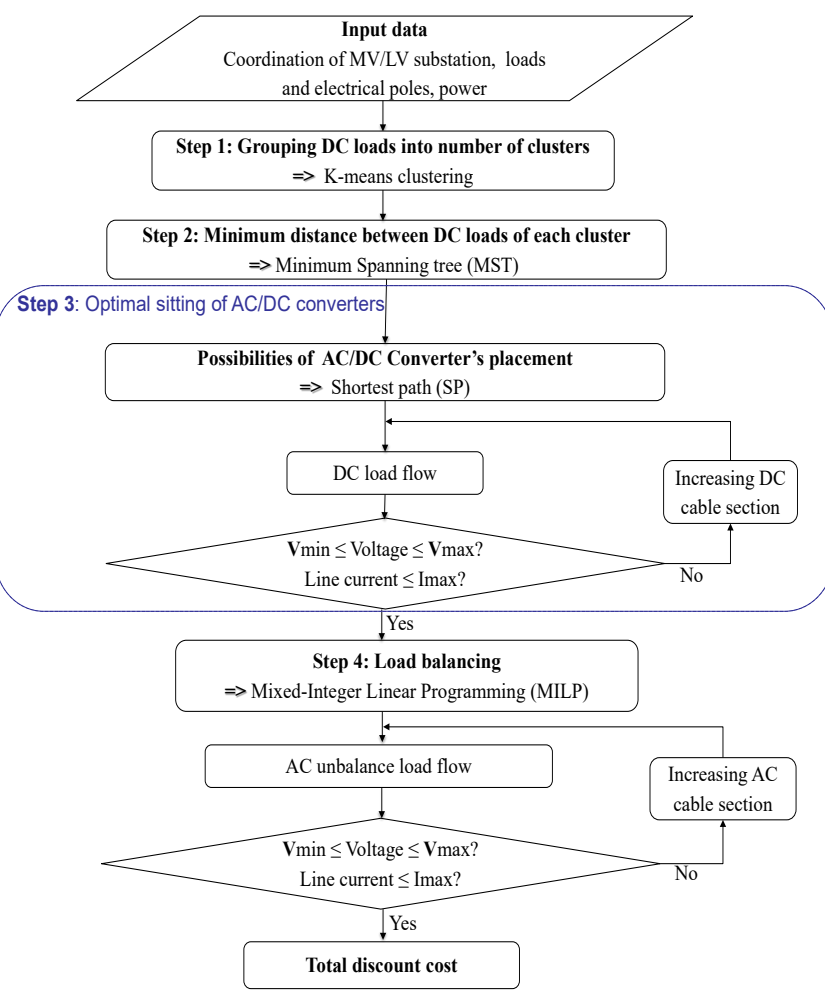

Fig. 1 Flowchart of the proposed method

\subsection{K-means clustering technique}

$\mathrm{K}$-means technique is the algorithm aiming at grouping objects into a given set of clusters which is classified by a user-defined number of clusters $\mathrm{K}$. This clustering technique minimizes the square error of Euclidean distance to cluster centers in order to minimize the total distances of clusters. The objective function $F$ is given as follows[8]:

$$
\text { Minimize } F=\sum_{j=1}^{K} \sum_{i=1}^{M}\left\|x_{i}^{j}-c_{j}\right\|^{2}
$$

where
$i$ : index of loads
$j:$ index of clusters
$M$ : number of data
$K$ : number of clusters
$\left\|x_{i}^{j}-c_{j}\right\|^{2}$ is a distance measure between a data point $x_{i}^{j}$ and the cluster center $c_{j}$.

\subsection{Minimum Spanning Tree (MST)}

The minimum spanning tree (MST) is a set of the edges of a graph $G$ that connects all the vertices together, with the minimum total edge weight and without any loops[9]. The sum of the edge weight of the spanning tree is as small as possible. If we consider a graph $G=(V, E)$ that consists of a vertices and edges [10]:

$$
\begin{aligned}
& V=\left\{v_{1}, v_{2}, \ldots, v_{n}\right\} \\
& E=\left\{e_{1}, e_{2}, \ldots, e_{n}\right\}
\end{aligned}
$$

The small possible weigh of $\sum_{i=1}^{n} e_{i}$ is the minimum spanning tree. Fig. 2 shows the result of the minimum spanning tree from a given graph.

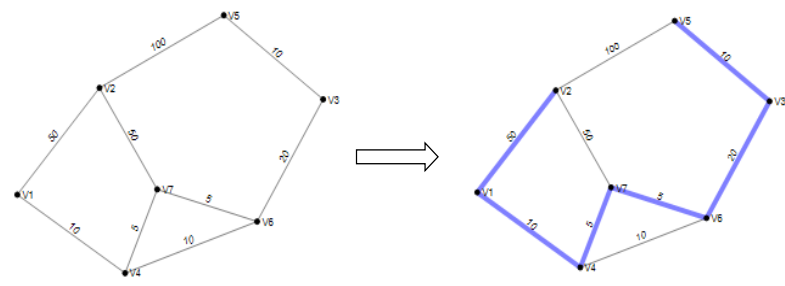

Fig. 2 Example of the MST of a given graph

\subsection{Shortest Path (SP)}

The algorithm aims at finding the shortest distance between the MV/LV substations and each DC load of the cluster through electrical poles [4]. Fig. 3 shows the pseudocode of the shortest path that finds the index of a load of each cluster and pole. Indeed, it defines the optimal path which connects from a pole to its closest DC load regarding the DC power loss.

$$
\begin{aligned}
& K: \text { number of clusters } \\
& n: \text { number of loads in a cluster } \\
& P: \text { number of poles } \\
& d(a, b): \text { distance bewteen } \text { a and } b \\
& \text { for } i=1: K \\
& \text { for } j=1: n \\
& \text { for } k=1: P \\
& \quad d_{i}=d(j, k) \\
& \quad D_{i}=\min \left(d_{i}\right) \\
& \text { index }=\text { find }\left(d_{i}=D_{i}\right) \\
& \text { end } \\
& \text { end } \\
& \text { end }
\end{aligned}
$$

Fig. 3 Pseudocode of the shortest path

\subsection{Phase balancing problem}

The load allocation algorithm has been formulated by using the Mixed Integer Linear Programming (MILP) tool of MATLAB (i.e. linprog). The objective is to balance the total power of three-phase to which clusters have been connected. Equation (4) is the objective function subjected to constraints (5) to (9)

$$
\min _{x}\left(\sum_{j=1}^{3} \varepsilon_{j}^{-}+\varepsilon_{j}^{+}\right)
$$




$$
\begin{gathered}
\sum_{i=1}^{N} P_{l}(i) \times x_{j}^{i}-\varepsilon_{j}^{-}+\varepsilon_{j}^{+} \leq \frac{P_{\text {total }}}{3}, \forall j=1: 3 \\
\sum_{j=1}^{3} x_{j}^{i}=1, \forall i=1: N \\
0 \leq x_{j}^{n} \leq 1, \forall j=1: 3 \& n \in[1 ; N] \\
0 \leq \varepsilon_{j}^{-} \leq+\propto, \forall j=1: 3 \\
0 \leq \varepsilon_{j}^{+} \leq+\propto, \forall j=1: 3
\end{gathered}
$$

- $P_{l}(i)$ is the maximal power of load $\mathrm{i}$

- $P_{\text {total }}$ is the total power consumed by the loads

- $x_{j}^{n}=1$ if cluster $\mathrm{n}$ belongs to phase $\mathrm{j}$ and 0 otherwise;

- $\mathrm{N}$ is the number of nodes of the power systems

- $\varepsilon_{j}^{+}$is the positive difference power of phase $\mathrm{j}$.

- $\varepsilon_{j}^{-}$is the negative difference power of phase $\mathrm{j}$.

\subsection{Actualized cost}

The total actualized cost of the network is used to calculate the cost over $\mathrm{T}$ planning year. It is divided into capital expenditure (CAPEX) and operational expenditure (OPEX). Equation (10) gives the actualized cost [11]:

$$
\begin{gathered}
C_{\text {total }}=C A P E X+O P E X \\
C A P E X=C_{\text {cable }(A C+D C)}+C_{\text {converter }} \\
O P E X=\sum_{t=0}^{T} \frac{C \times P \operatorname{Ploss}(t)}{(1+i)^{t}}
\end{gathered}
$$

Where

$$
\begin{array}{ll}
C_{\text {total }} & : \text { total actualized cost }[\mathrm{kUSD}] \\
C_{\text {cable }(A C+D C)} & : \text { cost of AC and DC conductor [kUSD] } \\
C_{\text {converter }} & : \text { cost of converter }[\mathrm{kUSD}] \\
C & : \text { cost of } 1 \mathrm{~kW} \text { loss peak }[\mathrm{kUSD} / \mathrm{kW}] \\
P \operatorname{loss}(t) & : \text { peak power losses at year } \mathrm{t}[\mathrm{kW}] \\
\mathrm{i} & : \text { actualization rate } \% \\
\mathrm{~T} & : \text { planning period }
\end{array}
$$

\section{Case study}

\subsection{Description of the network}

A non-electrified village in a rural area, located in Sandek commune, Batheay district, Kampong Cham, Cambodia from the previous study of the thesis [12] has been used in this paper. The 107 households are single-phase loads located along the side of the street with a total power of $43 \mathrm{~kW}$ and 22 electrical poles. Fig. 4 shows the DC households and electrical poles located along the road, which is supplied by an $\mathrm{MV} / \mathrm{LV}$ distribution transformer $(22 \mathrm{kV} / 0.4 \mathrm{kV})$ via $\mathrm{AC} / \mathrm{DC}$ converters. With the possibility of PV and battery storage integration system in the future, the $50 \mathrm{Vdc}$ voltage level was selected regarding the consumers in a rural area with various low power appliances [13]. Moreover, detailed information on DC conductors was provided in [14].

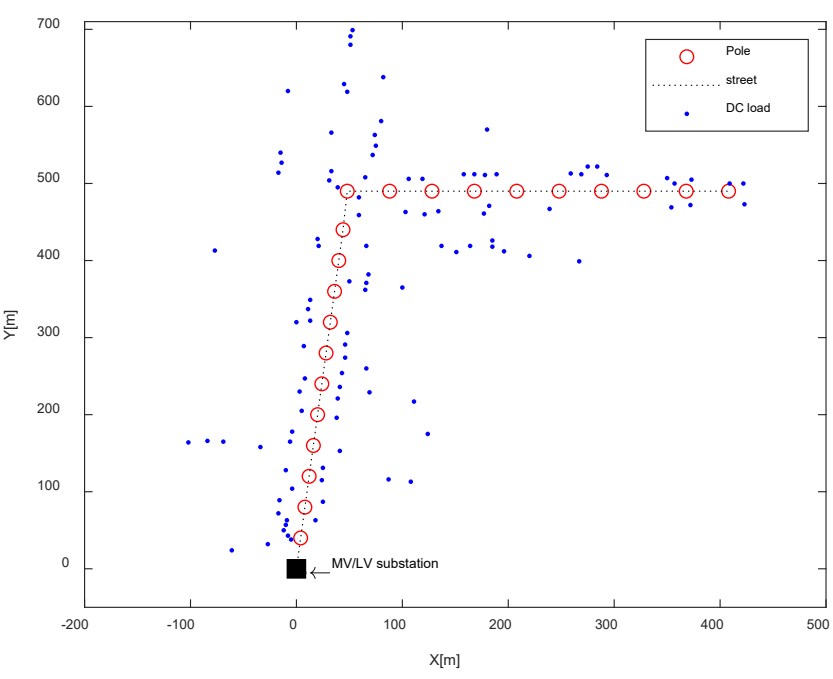

Fig. 4 Case study: electrical poles and loads

\subsection{Results and discussion}

Loads are packed into an optimal number of clusters $\mathrm{K}=16$ by using the K-means clustering technique as shown in Fig. 5. By selecting the number of clusters, thank to the Elbow method that looks at the percentage of variance as a function of the number of clusters.

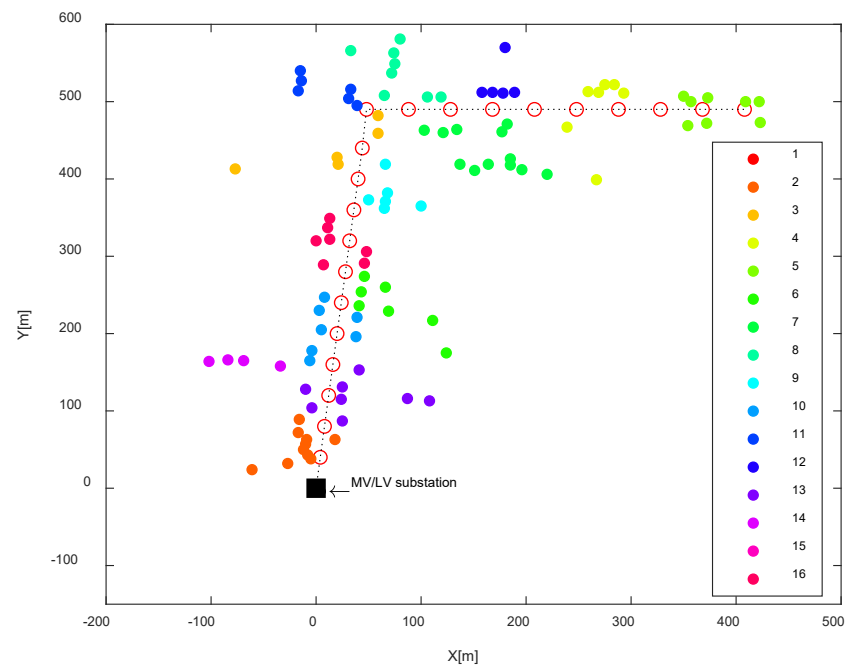

Fig. 5 Loads classified by K-means clustering technique

As a result of $\mathrm{K}=16$ clusters, to supply DC loads, we also need $16 \mathrm{AC} / \mathrm{DC}$ converters. The MST finds the minimum DC length of the conductors for each cluster and the SP finds the closest poles to clusters where we sit the AC/DC converters. Fig. 6 shows AC/DC converters that have been mounted on the poles to supply DC loads in each cluster and the structure of each cluster. The total length of clusters is $4345 \mathrm{~m}$ added by $1243 \mathrm{~m}$ of the total DC connection's length from clusters to poles. To avoid confusion with the numbering on the graph, we start clusters numbering from $23^{\text {rd }}$ (after 22 poles) so we have a cluster $23^{\text {rd }}$ to $38^{\text {th }}$ ( 16 clusters). 


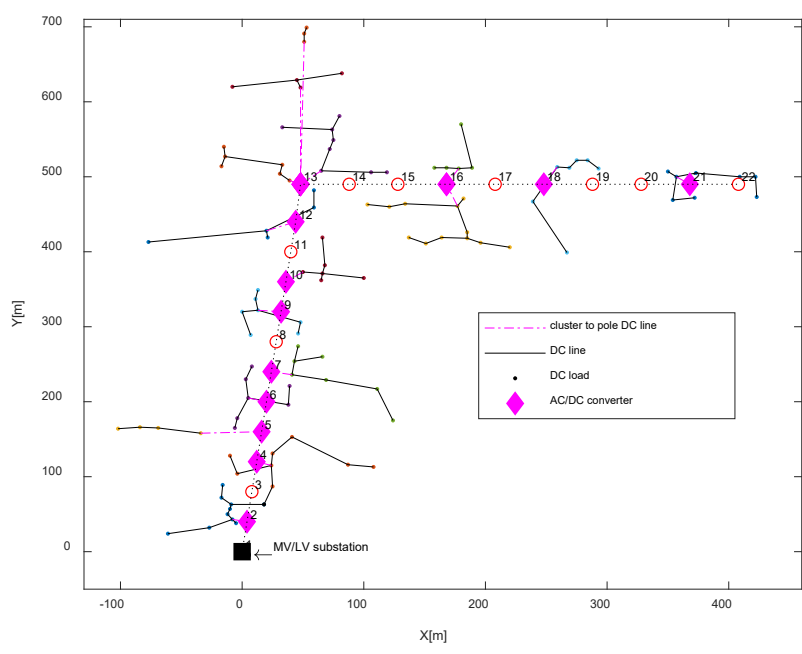

Fig. 6 Application MST to clusters creating DC structure

Fig. 7 shows the topology of the AC/DC distribution network. Each cluster was supplied and allocated by a phase of the three-phase 4 wires system in order to ensure a balance of the loads for the AC distribution system.

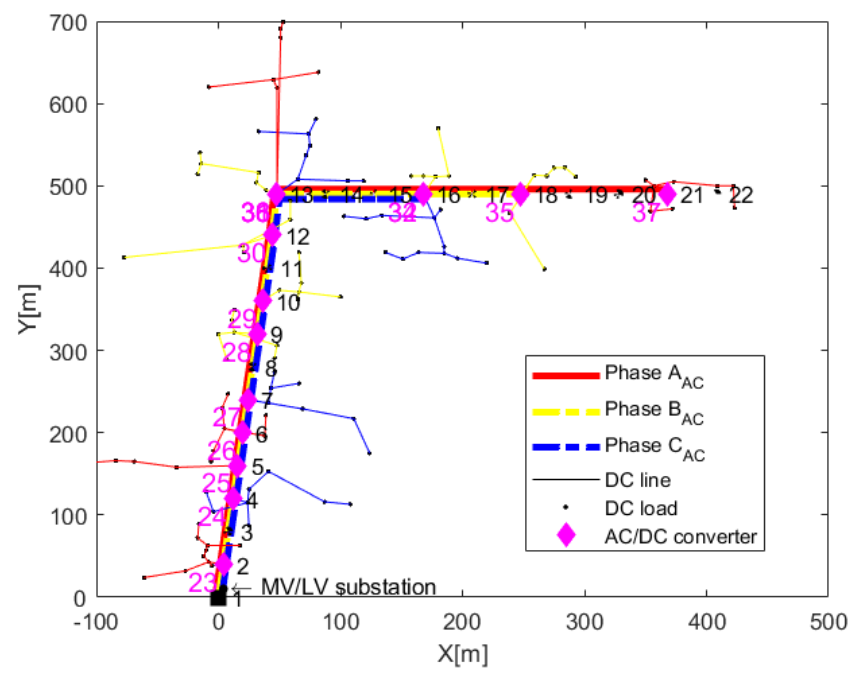

Fig. 7 Radial AC/DC low voltage distribution system

Table 1 The summary result of the simulation

\begin{tabular}{ll}
\hline Item & value \\
\hline Number of clusters. & 16 \\
Total length of AC main feeder. & $2929 \mathrm{~m}$ \\
Total length of DC conductor. & $5589 \mathrm{~m}$ \\
Total power losses. & $4.25 \mathrm{~kW}$ \\
Power per Phase A & $15.51 \mathrm{~kW}$ \\
Power per Phase B & $15.50 \mathrm{~kW}$ \\
Power per Phase C & $15.50 \mathrm{~kW}$ \\
Total discount cost (CAPEX+OPEX) & $152.58 \mathrm{kUSD}$
\end{tabular}

The summary result of the simulation is shown in Table 1 . Thanks to the MILP algorithm, the power consumption of each phase is almost balanced. The total power losses were $4.25 \mathrm{~kW}$ (about $9.88 \%$ of the total power consumption) which includes the AC and DC power losses. Furthermore, the total discount cost is $152.58 \mathrm{kUSD}$ that consisting of the CAPEX and OPEX. The CAPEX includes the AC and DC conductor cost, as well as AC/DC converter cost while the OPEX is an operational cost over 20 years of planning with an interest rate of $6 \%$ which includes only losses of the conductor.

Moreover, in Fig. 8, with the cross-section of $70 \mathrm{~mm}^{2}$ of $\mathrm{AC}$ main feeders, the AC voltage profile of poles was respecting the voltage constraint of the LV system in Cambodia [0.90pu, $1.06 \mathrm{pu}]$. On pole $18^{\text {th }}$ which is connects to cluster $35^{\text {th }}$, the lowest voltage was $0.9335 \mathrm{pu}$.

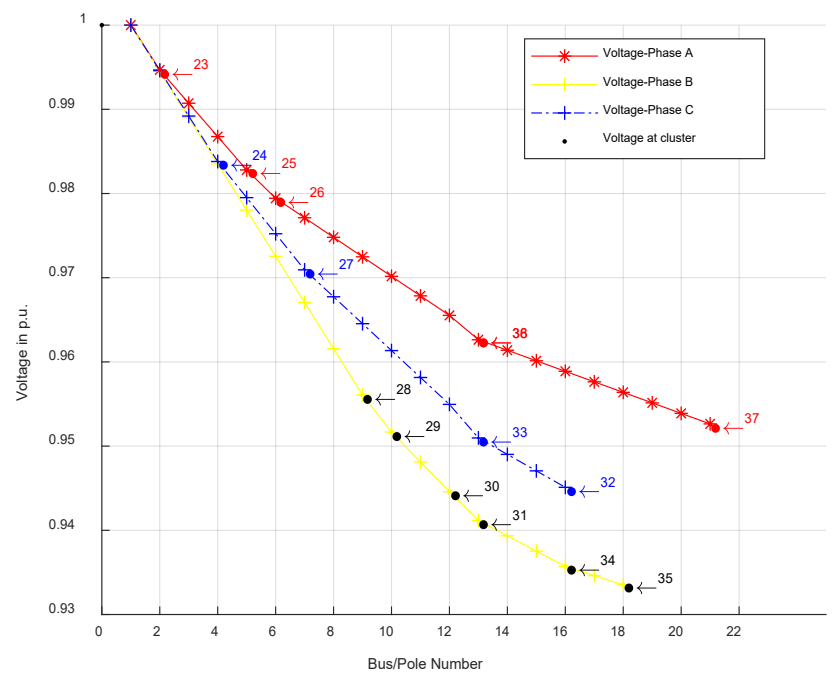

Fig. 8 AC voltage profile of poles and clusters

Also, Fig. 9 shows the percentage voltage deviation of each cluster. All DC loads' voltages were classified by clusters. In each cluster, the bottom and the top edge of the box indicate the $25^{\text {th }}$ and $75^{\text {th }}$ percentiles of the cluster while the central red mark indicates the median. The lowest and highest voltage observed, are also indicated. Indeed, the ' + ' symbol is the voltage value greater than the interquartile value $\left(75^{\text {th }}\right.$ $25^{\text {th }}$ ) and it is called an outlier.

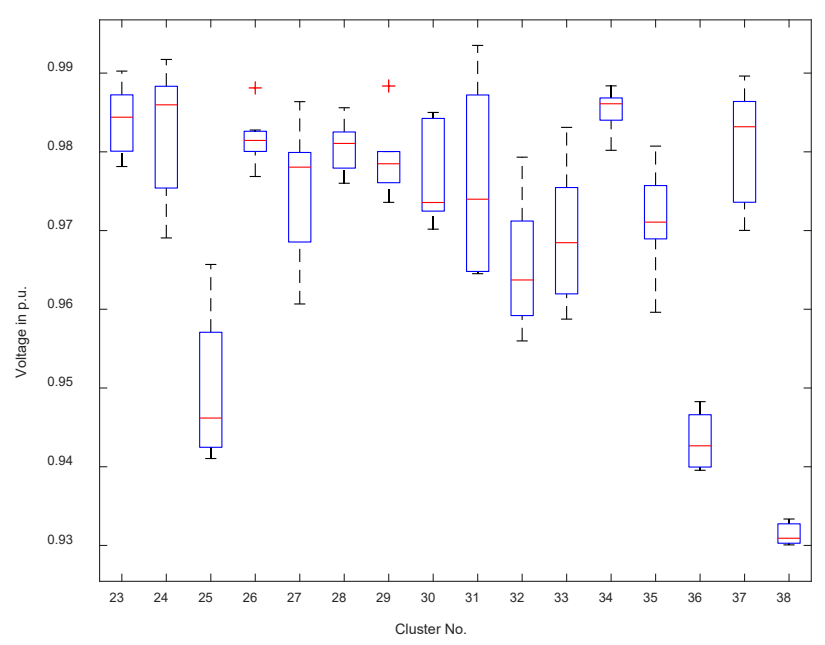

Fig. 9 Summary of DC voltage of clusters with a box plot

For the example of cluster $26^{\text {th }}$, the median was $0.9814 \mathrm{pu}$, and the bottom and top edge are 0.98pu and $0.9826 \mathrm{pu}$ respectively while the lowest and highest voltage are $0.977 \mathrm{pu}$ and $0.988 \mathrm{pu}$. It is noticed that the voltage $0.988 \mathrm{pu}$ is also 
considered as outlier ' + '. For cluster $38^{\text {th }}$, we noticed that its voltage is the lowest among clusters however, the lowest value of it is $0.93 \mathrm{pu}$ which does not violate the voltage constraint $(0.90 \mathrm{pu})$.

Fig. 10 shows the different cross-sections of DC conductors of clusters in a $3 \mathrm{D}$ plot. It is noticed that cluster $32^{\text {nd }}$ has the biggest DC conductor of $50 \mathrm{~mm}^{2}$ to satisfy the voltage and current constraints because it has the biggest power and the longest length of conductor in this cluster.

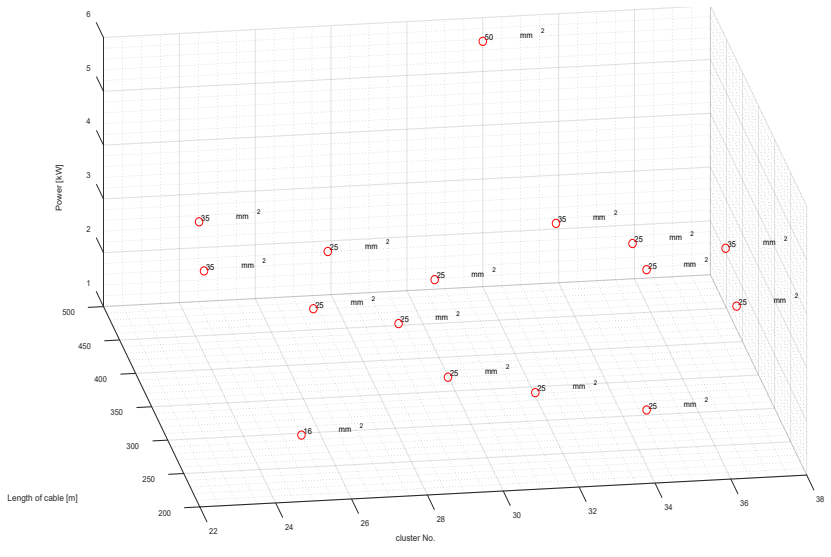

Fig. 10 Cross-section of DC conductor of clusters

\section{Conclusion and future work}

This paper addresses a novel algorithm tackling the traditional AC distribution network by proposing a novel architecture of AC/DC microgrid. The DC loads were packed into the optimal number of the cluster by K-means. The MST ensured the minimum length of all clusters. Indeed, the allocated power of each phase was balanced by using the MILP solver. Lastly, the algorithm has found the topology and total actualized cost of the AC/DC microgrid. In future work, the sitting and sizing of PV and storage in the cluster of the AC/DC microgrids will be investigated.

\section{Acknowledgements}

The authors would like to thank the support co-funded by the French Government Scholarship (BGF) and the Ministry of Education, Youth and Sport (MoEYS) of Cambodia for providing financial support of this research under the Higher Education Improvement Project (HEIP) with sub-agreement no. HEIP-ITC-SGA\#07 at the Institute of Technology of Cambodia (ITC).

\section{References}

[1] L. Mackay, "Steps towards the universal direct current distribution system," Delft University of Technology, 2018.

[2] W. N. J. Jaramillo, Paulina, Taneja, Jay et al., "Enabling private sector investment in microgrid-based rural electrification in developing countries: A review," Renew. Sustain. Energy Rev., vol. 52, pp. 1268-1281, Aug. 2015.

[3] V. Gouin, M. C. Alvarez-Hérault, and B. Raison, "Innovative planning method for the construction of electrical distribution network master plans," Sustain. Energy, Grids Networks, vol. 10, pp. 84-91, Jun. 2017.

[4] V. Vai, M.-C. Alvarez-Hérault, L. Bun, et al., "Design of LVAC distribution system with PV and centralized battery energy storage integration - a case study of Cambodia," ASEAN Eng. J., vol. 9, no. 2, 2019.

[5] V. Vai, E. Gladkikh, M. C. Alvarez-Hérault, et al.,, "Planning of low-voltage distribution systems with uncertainty on load demand in urban areas," in IEEE International Conference on Environment and Electrical Engineering and 2017 IEEE Industrial and Commercial Power Systems Europe, Milan, Italy, 2017.

[6] V. Vai, L. Bun, K. Khon, et al., "Integrated PV and Battery Energy Storage in LVAC for a Rural Village: A Case Study of Cambodia," in IECON 2020 The 46th Annual Conference of the IEEE Industrial Electronics Society, Singapore, 2020, pp. 1602-1607.

[7] V. Vai, M. Cecile Alvarez Herault, B. Raison, et al., "Optimal Low-voltage Distribution Topology with Integration of PV and Storage for Rural Electrification in Developing Countries: A Case Study of Cambodia," J. Mod. Power Syst. Clean Energy, vol. 8, no. 3, pp. 531-539, 2020.

[8] A. Rajabi, M. Eskandari, M. J. Ghadi, et al.," "A comparative study of clustering techniques for electrical load pattern segmentation," Renew. Sustain. Energy Rev., p. 109628, Dec. 2019.

[9] J. B. Kruskal, "On the Shortest Spanning Subtree of a Graph and the Traveling Salesman Problem," Source Proc. Am. Math. Soc., vol. 7, no. 1, pp. 48-50, 1956.

[10] P. C. Pop, “The generalized minimum spanning tree problem: An overview of formulations, solution procedures and latest advances," Eur. J. Oper. Res., vol. 283, no. 1, pp. 1-15, May 2020.

[11] M. C. Alvarez-Hérault, D. Picault, R. Caire, et al., "A novel hybrid network architecture to increase DG insertion in electrical distribution systems," IEEE Trans. Power Syst., vol. 26, no. 2, pp. 905-914, May 2011.

[12] V. Vai, "Planning of low voltage distribution system with integration of PV sources and storage means-Case of power system of Cambodia," University Grenoble Alpes, 2017.

[13] E. Rodriguez-Diaz, F. Chen, J. C. Vasquez, et al., "Voltage-Level Selection of Future Two-Level LVdc Distribution Grids: A Compromise between Grid Compatibiliy, Safety, and Efficiency," IEEE Electrification Magazine, vol. 4, no. 2, Institute of Electrical and Electronics Engineers Inc., pp. 20-28, 01-Jun-2016.

[14] METSEC CABLES LIMITED, "Cable Products Price List,",http://www.metsec.co.ke/images/docs/cables.pdf.

Accessed: 20-Nov-2020. 